\title{
Habilidades especializadas do tênis: um estudo de intervenção na iniciação esportiva com crianças escolares
}

CDD. 20.ed. 152.3

796.34
Constance Muller PÍFFERO*
Nadia Cristina VALENTINI*
*Escola de Educação

Física, Universidade

Federal do Rio Grande do Sul.

\section{Resumo}

0 objetivo desta pesquisa, de delineamento quase-experimental e correlacional, foi verificar a influência de um Programa de Iniciação ao Tênis (PIT) com duas abordagens, Clássica (AC) e de Contexto Motivacional para a Maestria (AM), no desempenho de habilidades motoras especializadas do Tênis (HMET) e investigar as associações entre o desenvolvimento das habilidades especializadas e as fundamentais. Participaram do estudo 61 crianças (29 meninas e 32 meninos), com idades de seis a 12 anos $(M=9,4)$, sendo 30 crianças da AC e 31 crianças da AM. Para as avaliações das crianças foram utilizados o Test of Gross Motor Development-2 (TGMD-2) e o instrumento de Habilidades Motoras Especializadas do Tênis (HMET). 0 PIT foi desenvolvido em 26 semanas, implementando, para a AM os pressupostos da estrutura TARGET e do Sport Education Model e para a AC os modelos clássicos de aprendizagem do Tênis. Os resultados indicaram que 1) mudanças positivas e significantes $(p<0,01)$ nas HMET para todas as crianças; 2$)$ interação não significante da faixa etária $(p=0,519)$ e do gênero $(p=0,24)$ nas HMET; 3) associação restrita a locomoção no pós teste entre habilidades especializadas e fundamentais para o grupo da maestria. A implementação de um Programa de Iniciação ao Tênis, baseado em propostas metodológicas eficazes e condizentes com as necessidades reais dos participantes, promove ganhos motores que contribuem para o desenvolvimento infantil.

UnITERMos: Aprendizagem; Destreza motora; Tênis.

\section{Introdução}

O processo de tornar-se habilidoso é dinâmico e está em constante mudança ao longo da vida, no qual, mudanças em uma ou mais variáveis, podem levar o sistema a uma nova organização e, consequentemente, na busca de um padrão estável (Clark \& MetCalfe, 2002; Gallahue \& OzMUN, 2001). Os padrões estáveis representam comportamentos que são reprodutíveis e independentes, entretanto, para atingir-se a estabilidade, o sistema passa por períodos de instabilidade, ou seja, para ocorrer a aprendizagem o estado estável deverá dar caminho a um novo estado dinâmico, e assim sucessivamente. Por meio desse processo, os movimentos são combinados das formas mais variadas e são aperfeiçoados, determinados pelas características específicas de cada tarefa em um esporte particular.

A consistência do indivíduo no desempenho das habilidades motoras especializadas está sustentada na qualidade com a qual as habilidades motoras fundamentais foram aprendidas e refinadas (CLARK \& Metcalfe, 2002; Gallahue \& Ozmun, 2001). A progressão bem sucedida do movimento ao longo das fases de transição, aplicação e utilização permanente em tarefas motoras depende de desempenhos apropriados na fase motora fundamenta (GALLAHUE \& Ozmun, 2001). Novas habilidades motoras são incorporadas à medida que há um melhor desempenho provindo de muitas horas de prática deliberada; com a prática deliberada o indivíduo aprimora seu repertório motor geral e em um domínio específico, pois a demanda da prática para tornar o movimento especializado termina por restringir os domínios de especialização (ERICSON \& LeHMANN, 1996).

Como ocorre a aquisição e o refinamento das habilidades não é preocupação somente de pesquisadores, a sua investigação repercute diretamente na prática da Educação Física. Profissionais da área de Educação 
Física têm demonstrado uma grande preocupação com questóes relacionadas ao ensino e à aprendizagem da atividade motora, seja ela direcionada ao esporte competitivo, lazer ou estilo de vida ativo (BALBINOTTI, Balbinotti, Marques \& Gaya, 2004; Bento, Garcia \& GraÇa, 1999; Gaya, Marques \& Tani, 2004; Mesquita, 2004, 2005; Valentini \& Toigo, 2005).

Entretanto, as pesquisas não são necessariamente incorporadas por educadores e, não obrigatoriamente, respondem as questōes da prática. LANGLEY e WOODS (1997) apontam para a dificuldade dos educadores em usar pesquisas para guiar estudantes para a conquista de metas motoras. Os autores reforçam a dificuldade destes em desenvolver treinamentos que conduzam a novos patamares motores que incorporem as variadas habilidades utilizadas em um jogo específico. Educadores, em geral, têm dificuldades em saber como reduzir ou aumentar a complexidade de tarefas que enfatizem as condições específicas de cada esporte e a aquisição de habilidades mais sofisticadas (LANGLEY \& Woods, 1997). Muitas vezes educadores desconhecem as potencialidades das crianças mostrando-se pouco capazes de realizar programas que desenvolvam as habilidades motoras, intelectuais e afetivas desses grupos; propondo atividades que não possibilitam ampliação e diversificação, inibindo e restringindo o desenvolvimento e desconsiderando as reais necessidades (Canfield \& NetTo, 1992). Muitas vezes as tarefas propostas pelo educador exigem desempenhos superiores aos apresentados pelas crianças, o que pode desviar seus interesses, levando-as a desmotivação e a perda do gosto pela prática. A implementação de tarefas mais complexas e contextualizadas nos treinamentos ou nas aulas de Educação Física incorporaram a instabilidade do jogo e conduzem ao desenvolvimento motor superior quando comparadas a práticas menos complexas (CANField \& NeTto, 1992).

Como os educadores físicos podem usar diversas estratégias para ensinar o esporte por meio de jogos tem sido também o foco de alguns estudos (Doolittle, 1995; Metzler, 1990; Siedentop, 1994). Metzler (1990) observa que a maioria dos estudantes expressava prazer na prática do jogo e frequentemente prefere esta aula à prática de habilidades técnicas. Vários autores (CANFIELD \& Netto, 1992; Doolittle, 1995; Langley \& Woods, 1997; Metzler, 1990; Siedentop, 1994; VALENTINI \& Tolgo, 2005) sugerem a organização da aula de forma a contemplar equilibradamente o desenvolvimento técnico e o jogo. Esta estratégia permite aos estudantes continuar desenvolvendo novas habilidades com a aplicação das mesmas no decorrer dos jogos. Assim, o enfoque é direcionado à prática do jogo como meio de desenvolver habilidades específicas; e, a prática de habilidades específicas como meio de se manter efetivamente atuante no jogo (VAlentini \& Toigo, 2005).

DoOlTtLe (1995) também propõem a aprendizagem esportiva pelo jogo para indivíduos iniciantes com a simplificação das regras, a adaptação da bola e da quadra, onde o aluno possa enfocar o jogo ao invés de preocupar-se em executar as habilidades com certo desempenho. Nesta proposta pedagógica o estudante estaria mais empenhado em descobrir os problemas e as estratégias comuns aos jogos com rede e criaria seus próprios caminhos para ganhar os pontos. DoOLITTLE (1995) sugere ainda que, gradualmente, os materiais e espaços sejam substituídos pelos de origem. Salienta a autora, que muitos estudantes com poucas habilidades encontram seu sucesso inicial nos aspectos cognitivos que compóem a ideia global do jogo. Ao demostrarem competência quando questionados a buscar soluções aos desafios típicos dos jogos, os alunos passam a entender a necessidade de utilizar diferentes estratégias ofensivas e defensivas, evidenciando mais interesse na prática e refletindo sobre o porquê da necessidade de tal habilidade antes de executá-la, motivando-se mais para aprender.

YounG (1985) sugere que a valorização da aprendizagem ocorre em exercícios no formato de drills; pois estas tarefas repercutem no refinamento da técnica e, consequentemente, no aumento na motivação do aluno para continuar praticando. YounG destaca que muitos alunos do ensino médio, principalmente os pouco habilidosos, não valorizam esta prática, pois somente encontram prazer no jogo em si. Os alunos mais habilidosos têm uma melhor percepção da importância dos "drills" na busca do refinamento e na melhora na execução, mas, no entanto, os menos habilidosos não fazem esta conexão e percebem esta prática como entediante. Segundo o autor, se a prática fosse efetiva, seria improvável que estudantes não percebessem e não estabelecessem uma relação entre a prática de "drills" e o padrão global do jogo. Conclui que a transferência do aprendizado adquirido através de "drills" para o jogo poderia auxiliar os estudantes a usar o tempo de aprendizagem mais produtivamente e que este processo de conscientização é uma função do educador.

Ainda com um enfoque direcionado a maximizar a aquisição de habilidades específicas e o aproveitamento de uma aula usando sequências de "drills", HEATH, BLACKWELL e MODDALOZZO (1995), desenvolveram técnicas de ensino que priorizam informações sensoriais sobre 
a tarefa por meio da prática correta de cada habilidade e da frequência apropriada de "feedback" dada pelo professor. Ao planejar uma aula, sugerem diferentes autores, o professor deve estar atento ao número de aquisições que serão exigidas e o correspondente "feedback" sobre cada uma delas, oportunizando, assim, um aprendizado mais complexo (HEATH, BlackWell \& ModDalozzo, 1995; Valentini \& ToIgo, 2005). O "feedback" apropriado durante os drills é determinante na aquisição de habilidades motoras, pois propicia ao indivíduo utilizar-se de informações intrínsecas e extrínsecas. Para a aquisição de habilidades motoras é imprescindível a percepção do indivíduo sobre seu próprio desempenho e também as informações provindas do professor.

Observa-se portanto que diferentes abordagens têm sido utilizadas no processo ensino-aprendizagem das habilidades motoras. $\mathrm{O}$ processo de ensino clássico na iniciação esportiva do Tênis tem sido centrado: 1) no desempenho competitivo e aprimoramento técnico dos movimentos; 2) na execução eficiente dos golpes e suas variações, e a utilização dos mesmos no jogo; 3) nas questôes táticas que caracterizam a modalidade e os jogos simples ou de duplas; 4) no treinamento específico com repetições sistemáticas, "drills"; 5) no conhecimento das regras e de sua aplicação no jogo; (6) na figura do professor ou técnico, sendo ele o o mediador das decisóes tomadas relativas à aprendizagem e ao treinamento; 7) no planejamento sequencial das atividades adequadas aos níveis de habilidades e desempenho dos alunos; e, 8) no reforço dos aspectos psicológicos que envolvem a participação na competição, como: por exemplo a concentração e a autoconfiança (BURWASH, 1991; DENIAU, 1997; Douglas, 1982; Gallwey, 1996; Lendl \& Mendoza, 1987; MEINECKE \& SCHOTH, 1985; Mesquita, 2004; SturM, 1982; Tilden, 1982). Abordagens clássicas podem, muitas vezes, levar a exclusão dos menos habilidosos da prática em decorrência da pressão elevada por resuldados (Deniau, 1997; MArques, 2004; MEINECKE \& SCHOTH, 1979; MesQUITA, 2004; Siedentop, 1994; STURM, 1992; VALENTINI \& ToigO, 2005). Nessas abordagens os modelos de ensino para crianças seguem os mesmos pressupostos e organização do ensino generalizado do Tênis para os adultos (Galliette, 1996; Meinecke \& Schoth, 1985).

Embora as abordagens clássicas sejam comumente adotadas no meio esportivo, outras propostas metodológicas têm sido desenvolvidas, especialmente no processo de ensino-aprendizagem de crianças e adolescentes cujo o foco tem sido a autonomia e a participação de todos, do mais ao menos habilidoso.
Alguns pressupostos são comuns nessas abordagens: 1) respeitar as características individuais, experiências prévias e diferentes níveis de habilidades, viabilizando o sucesso no aprendizado para todas as crianças; 2) utilizar como parâmetros avaliativos, auto-referênciados, o esforço, a persistência e a dedicação para a conquista da maestria em diversas habilidades; 3) envolver as crianças no processo de compreensão sobre como ocorre o aprendizado, elegendo-os sujeitos de seu próprio desenvolvimento; 4) propor tarefas que instiguem a busca de constantes desafios; 5) implementar a novidade nas atividades; 6) organizar estruturas cooperativas para a tomada de decisões e determinação de regras e responsabilidades envolvendo alunos nos papéis de liderança; 7) o ensino em pares, pequenos e grandes grupos independentemente dos níveis de habilidades de cada um; 8) o processo de auto-avaliação dos alunos sobre as suas atitudes, conquistas e desempenhos; e, 9) incluir os participantes do processo de decisões como forma de promover o engajamento do indivíduo e a participação autonoma (Alexander \& Luckman, 2001; Browne, Carlson \& Hastie, 2004; Siedentop, 1994; Valentini \& Rudisill, 2004a, 2004b; Valentini, Rudisill \& GOODWAY, 1999a, 1999b; WALLHEAD \& NTOUMANIS, 2004). Em geral, as estrategias tem sido implementadas ao longo da estrutura TARGET, sendo utilizadas as letras como referenciais de denominação de cada dimensão do ensino: Tarefa (Task), Autoridade (Authotity), Reconhecimento (Recognition), Grupo (Grouping), Avaliação (Evaluation) e Tempo (Time) (Ames, 1992a; EPSTein, 1988; VAlentini, Rudisill \& GOODWAY, 1999a, 1999b).

Muitos dos prícncipios do Contexto motivacional para a maestria se assemelham à príncipios do Modelo de Educação Esportiva (SiEDENTOP, 1994) cujo o principal objetivo é, utilizar o esporte para promover experiências ricas por meio de movimentos que possibilite ao estudante desenvolver suas potencialidades, exercer o convívio social, ampliar as relações de amizade, vivenciar o trabalho em equipe, gerar resoluções de problemas na prática de jogos, desenvolver condutas esportivas apropriadas através do jogo, do respeito às regras, assumir papéis de liderança e experimentar o prazer e o divertimento (Alexander \& Luckman, 2001; GraçA, 2004). Neste modelo o esporte na escola, parte essencial do currículo, promove a qualidade de vida dos alunos, a integração social, a vivência da cultura esportiva e a adoção de um estilo de vida saudável e prazeroso (GraçA, 2004). Siedentop (1994) propõe uma perspectiva inclusiva, adaptando estratégias de ensino 
para atender e acomodar os diferentes níveis de habilidades motoras, criando jogos que propiciem o aprendizado das habilidades esportivas específicas de forma progressiva e complementar (JEWETT, BAIN \& ENNIS, 1995). O comprometimento com as tarefas é fundamental, uma vez que a proposta enfatiza não somente a aquisição de habilidades motoras, como também as habilidades cognitivas, afetivas e sociais por meio do esporte (BROWNE, CARLSON \& Hastie, 2004; GraÇa, 2004; JeWETt, Bain \& EnNIS, 1995; Mesquita, 2004; WalHeAd \& NTOUMANis, 2004).

Portanto, a consideração dessas duas abordagens metodológicas que enfatizam a motivação e o engajamento na atividade física pode ser importante para o ensino do esporte para crianças, capaz de constituir-se em uma proposta adequada a todos. As pesquisas (AleXander \& LUCKMAN, 2001; BROWNE, Carlson \& Hastie, 2004; Epstein, 1988; Valentini \& Rudisill, 2004a, 2004b; WALlHEAD \& NTOUMANIS, 2004) sugerem que os benefícios da implementação de uma pedagogia adequada às necessidades dos alunos devem ser sempre avaliados, permitindo práticas de qualidade. A implementação de programas interventivos que primem por abordagens consistentes podem ser implementados com o intuito de maximizar a inclusão e a permanência de crianças no esporte. Desenvolvendo valores e autoconfiança; vivenciando prazer nas suas relaçóes pessoais; participando de tomadas de decisões (Araújo, Davids \& Serpa,

\section{Método}

\section{Participantes e critérios de composição da amostra}

Participaram desta pesquisa, quasi-experimental e correlacional, crianças $(\mathrm{N}=61)$ cadastradas em um programa de educação pelo esporte. Os participantes 32 de meninos e 29 meninas com idades de sete a 11 anos $(M=9,4 \pm 1,86)$, foram distribuídos em quatro grupos estratificados por idade (sete a nove anos e 10 a 11 anos) e gênero, dois grupos com Abordagem Clássica e dois grupos com Abordagem de Contexto Motivacional para a Maestria. Todas os resultados das crianças do programa de intervenção foram mantidas e consideradas para as análises estatística dos dados, independente do número de faltas, partindo do princípio que este é o procedimento escolar padrão. As crianças frequentavam escolas públicas e viviam em moradias de até três peças, em bairros pobres e
2005; Laguna, 2005; Mesquita, 2005; TheEBOOM, De Knop \& Weiss, 1995; Valentini, Rudisill \& GoOdWAY, 1999a, 1999b; Valentini \& Toigo, 2005; WeIss, 1991). Portanto, os seguintes objetivos foram estabelecidos para este estudo: 1) verificar e comparar a influência de um Programa de Iniciação ao Tênis, com duas distintas abordagens, Clássica e de Contexto Motivacional para a Maestria, no desempenho de habilidades motoras especializadas do Tênis; 2) verificar a associação entre as habilidades motoras fundamentais e especializadas do Tênis; 3) verificar a influência da faixa etária e do gênero sobre as habilidades especializadas do Tênis das crianças que atendem o Programa de Iniciação ao Tênis. As seguintes hipóteses foram estabelecidades: 1) as crianças em ambas as abordagens demonstrariam mudanças positivas da pré para a pós-intervenção no desempenho das habilidades motoras especializadas do Tênis; 2) as crianças de ambas as abordagens demonstrariam desempenhos semelhantes, na pós-intervenção, nas habilidades motoras especializadas do Tênis; 3 ) as crianças mais velhas demonstrariam desempenhos superiores nas habilidades especializadas quando comparadas às mais jovens; 4) os meninos demonstrariam desempenhos superiores nas habilidades especializadas quando comparados às meninas; 5) impacto mais significativo da abordagem do contexto Motivacional para a Maestria nas habilidades motoras fundamentais de meninos e meninas.

com precária infra-estrutura, cujos pais têm ensino fundamental incompleto e recebem até um salário mínimo (Critério de Classificação Econômica Brasil, CCEB).O tamanho da amostra deste estudo foi baseado em pesquisas com delineamento de Intervenção Motora (Browne, CARLSON \& Hastie, 2004; Valentini \& Rudisill, 2004a, 2004b; Wallhead \& NTOUMANIS, 2004). Os pais ou representantes legais de todos os participantes assinaram o termo de consentimento livre e informado e esta pesquisa foi aprovada pelo Comitê de Ética da UFRGS.

\section{Instrumentos e coleta de dados}

Para avaliar o desempenho dos participantes em golpes básicos do Tênis (golpe de direita, golpe de esquerda, voleio de direita, voleio de esquerda, "smash" e saque) foi utilizado o teste de Habilidades 
Motoras Especializadas do Tenis (HMET) adaptado do teste Arbeitsmaterialen Zur Differentiellen Bewegungsanalyse Der Grundschlage im Tennis (1977). As habilidades são subdivididas em critérios de execução permitindo uma análise mais precisa dos movimentos e nos níveis de desempenho de cada habilidade, em particular. Os escores do teste variam de 0 a 2520 , sendo 140 itens pontuados de 0 a $6(0$ = não executa; 1 = executa parcialmente e 2 $=$ executa), para as três tentativas a serem pontuadas.

O HMET foi aplicado em uma amostra piloto de 30 crianças e jovens, pertencentes a uma escola de Tênis de um clube da cidade de Porto Alegre, sendo 10 iniciantes, 10 intermediários e 10 atletas competitivos. Os testes foram realizados e avaliados pela pesquisadora e re-aplicados após 12 dias, sendo todos os alunos filmados para posteriores avaliações e análises estatísticas. A fidedignidade do HMET no estudo piloto apresentou um resultado do coeficiente de correlação teste-reteste de $\alpha=0,98$ indicando que o instrumento era fidedigno na amostra piloto.

O HMET foi aplicado na pré-intervenção; reteste (intervalo de no máximo 14 dias), e na pós-intervenção. $\mathrm{O}$ teste foi aplicado pela pesquisadora em cada aluno, individualmente, filmado com câmera frontal executando três tentativas para cada golpe básico, com duração aproximada de 10 minutos e sendo utilizadas bolas de Tênis, 1 raquete de Tênis, uma câmera frontal e fita cassete. Conforme o protocolo, a pesquisadora forneceu previamente uma descrição verbal de cada golpe e duas tentativas para uma melhor compreensão da tarefa. As pontuações foram realizadas separadamente pela pesquisadora e por um avaliador cegado através das gravaçōes, com duração de cerca de 15 minutos para cada criança.

Para avaliar o desempenho motor nas habilidades motoras fundamentais foi utilizado o Test of Gross Motor Development 2, TGMD-2 (UlRICH,2000). O TGMD-2 compõe-se de 12 habilidades motoras fundamentais, subdivididas em dois sub-testes compostos por seis habilidades motoras de locomoção (correr, galopar, saltitar, saltar sobre o mesmo pé, saltar horizontalmente e correr lateralmente) e seis habilidades motoras de controle de objeto (rebater, quicar, receber, chutar, arremessar sobre o ombro e rolar). Os itens apresentados no teste são divididos por critérios, possibilitando à criança demonstrar competência na execução da habilidade avaliada.

O TGMD-2 foi aplicado em dois momentos: na pré-intervenção e na pós-intervenção. A aplicação foi feita individualmente ou em pares, sendo todos os avaliados filmados com câmera frontal, executando duas tentativas para cada habilidade motora, num tempo aproximado de 20 minutos para cada criança. Conforme o protocolo do teste, a avaliadora/pesquisadora demonstrou e fez uma descrição verbal de cada habilidade para as duplas, certificando-se de que as crianças haviam compreendido o que executar e reforçando as instruções quando necessário. Os escores foram obtidos por meio da anãlise dos vídeos, feitos pela pesquisadora e uma por um avaliador cegado. Os escores apresentados pelo teste incluem escores bruto, escores padrão, percentil para cada sub-teste (locomoção e controle de objeto) e a soma dos escores padrão. As análises estatísticas deste estudo foram baseadas no escore padrão por entender ser o escore que leva em consideração a idade precisa das crianças no momento das avaliações (pré e pós-intervenção).

\section{Implementação do programa de iniciação ao tênis}

As abordagens do Contexto Motivacional para a Maestria e Clássica ocorreram em turnos diferenciados para evitar que as crianças comparassem as propostas e materiais que diferiam entre si. Foram ministradas 40 sessões interventivas para cada um dos quatro grupos, totalizando 160 sessōes, duas vezes por semana para cada grupo. Dois professores de Educação Física colaboraram durante a implementação da intervenção e foram instruídos previamente sobre as abordagens e os planos de aula.

Condizentes com os pressupostos do Contexto Motivacional para a Maestria (GoOdway, 1999a, 1999b; Valentini \& Rudisill, 2004a, 2004b) e a proposta do Sport Education Model (SIEDENTOP, 1994) foram desenvolvidas estratégias para a abordagem para a maestria; e, condizentes com as abordagens tradicionalmente utilizadas no ensino do Tênis (Burwash, 1991; Douglas, 1982; LendL \& Mendoza, 1987; TiLden, 1982) foram desenvolvidas estratégias para a abordagem clássica. As sessōes foram organizadas com três momentos (introdução ao trabalho diário e orientações, prática das atividades, finalização com interação professor-aluno sobre as experiências vivenciadas). As atividades envolveram os golpes básicos do Tênis e o jogo. As atividades foram elaboradas em ordem de progressão e com níveis de dificuldade adequados às idades dos participantes para as duas abordagens, porém, estabelecendo as devidas diferenças pedagógicas para cada dimensão da estrutura TARGET - Task, Authority, Recognition, Groupping, Evaluation, Time (VALENTINI, 2002). 
Com relação a dimensão "Task", a organização curricular das tarefas motoras de adaptação, golpes de fundo, golpes de rede e jogos, enfatizaram princípios educativos do esporte, estimulando o jogo limpo, o respeito às regras e aos adversários e o espírito esportivo. Em ambas as abordagens o jogo foi aplicado e adaptado às capacidades dos alunos, no entanto, as abordagens diferiram entre si na forma com a qual as atividades foram apresentadas e nos materiais utilizados.

Para a Abordagem de Contexto Motivacional para Maestria foi implementado um programa de eventos variados, no qual os alunos participaram com sugestóes para a implementação, organização, elaboração dos prêmios, materiais de divulgação, bem como nos papéis de liderança e de colaboradores. Um evento festivo aconteceu no final da intervenção, nos moldes competitivos do esporte, onde foram criadas condições para que todos participassem, desempenhassem diversas funções (capitão, jogador, juiz, torcedor, divulgador, etc) e pudessem vivenciar experiências prazerosas e divertidas ao participarem de jogos esportivos. As atividades diárias foram praticadas em forma de circuito, com número de estações e exercícios que variaram conforme os objetivos de cada sessão. Também foram propostos exercícios que se alternaram em atividades individuais, em duplas, em pequenos grupos e em equipes, promovendo experiências de convívio social, cooperação, companheirismo e espírito de equipe. Os materiais e equipamentos foram adaptados e adequados às necessidades e condiçóes de utilização dos alunos. Assim, alternados as alturas e tipos de redes, os tamanhos das quadras, a diversidade de bolas, raquetes e outros materiais para que as crianças tivessem reais chances de adequar seus níveis de desempenho, de aumentar seu interesse em participar e em aprender, obtendo, assim, sucesso na realização das atividades. As tarefas que propiciaram a aprendizagem do jogo foram implementadas, seguindo uma progressão pedagógica adequada, através da diversificação de materiais e dos espaços físicos, de jogos adaptados e do jogo, propriamente dito. Foram implementados jogos nos quais as regras, as pontuações, o tempo e o número de participantes eram adaptados e as crianças desafiadas a aplicabrem estratégias e resoluções eficazes de problemas.

Para a Abordagem Clássica ao final da intervenção um evento competitivo nos moldes dos realizados por federaçôes de Tênis, respectivos à faixa etária. As atividades foram apresentadas em forma de exercícios de drills, efetivando o desempenho de habilidades motoras especializadas através $\mathrm{da}$ repetição sistemática dos golpes básicos do Tênis.
As atividades variaram em exercícios individuais, em duplas e em pequenos grupos, seguindo o formato proposto pelo esporte em questão e dando ênfase aos aspectos técnicos e a qualidade dos movimentos. Os materiais foram os específicos da modalidade (raquetes e bolas de Tênis, bolas de Tênis "Soft"), porém utilizando redes mais baixas e diminuindo as dimensōes das quadras nas fases iniciais do programa, a fim de otimizar a prática das atividades e motivar os alunos a participar. As tarefas foram elaboradas e apresentadas pela pesquisadora/ professora, a qual determinou as formações dos grupos e o tempo de prática das mesmas.

Com relação a dimensão "Authority" para a Abordagem do Contexto Motivacional para a Maestria foi implementada uma proposta conjunta na tomada de decisões entre pesquisadora/professora e alunos. Os alunos foram estimulados a participar nas escolhas dos pares, grupos e equipes, nas formas e ordens de participação nas atividades, na elaboração de regras e responsabilidades pessoais e do grupo. Foram implementadas atividades que promovessem a participação equitativa nos papéis que englobam a estrutura das sessões, dos jogos e das atividades competitivas. Com isso, os alunos exerceram funções de juizes, professores, coordenadores de equipe e jornalistas (criação de cartazes com fotos de revistas e dos próprios alunos), trabalhando de forma autônoma e cooperativa com a pesquisadora/ professora e os colegas. Atividades relativas à aprendizagem das regras do jogo formal estavam incluídas nas atividades diárias, porém, foram criadas e fornecidas súmulas adaptadas e oficiais para que os alunos pudessem aprender as funçōes de árbitro.

Quanto às atitudes socialmente aceitáveis durante a participação no Abordagem do Contexto Motivacional para a Maestria, as mesmas foram elaboradas coletivamente, professora e alunos, sendo que as crianças sugeriram os protocolos a serem adotados e como monitorá-los. No início do programa, foram combinadas as regras de comportamentos aceitos no contexto de aprendizagem (respeitar aos professores e colegas; cuidar, recolher, organizar e guardar os materiais; usar linguagem adequada; respeitar os horários; participar das atividades sem perturbar; ajudar os companheiros; etc). $\mathrm{O}$ não cumprimento das regras por eles estabelecidas, bem como as suas consequências, acarretaria em afastamento da atividade e na reincidência, a saída da sessão. Reuniōes entre pesquisadora/professora e alunos serviram para promover momentos de reflexão e análise e relatos individuais do andamento das atividades. 
Com relação a Abordagem Clássica, a pesquisadora/ professora foi a única responsável em determinar e orientar os procedimentos para a realização das tarefas e exercícios, centralizando em si as tomadas de decisão e responsabilidades. As atividades foram por ela previamente determinadas, seguindo os objetivos propostos pelo programa, cabendo a ela, também, a decisão sobre o tempo de duração das mesmas, as formações dos pares e grupos, a utilização dos materiais e os critérios relativos aos desempenhos motores apresentados pelas crianças. A pesquisado$\mathrm{ra} /$ professora estipulou regras de convivência, bem como as consequências pelo seu não cumprimento, nas quais foram enfatizadas as condutas adequadas ao convívio social em aula, o cumprimento dos horários, o cuidado com os materiais, o respeito com os colegas e pesquisadora/professora.

Com relação a dimensão "Recognition" o reconhecimento para a Abordagem de Contexto Motivacional para a Maestria foi caracterizado pela valorização do esforço demonstrado ao participar das tarefas propostas; empenho na superação dos próprios limites, da valorização das condutas esportivas apropriadas; cumprimento das regras; respeito pelos demais; espírito de equipe; e, da cooperação. A professora se utilizavam de dicas verbais, "feedbacks", elogios e palavras motivadoras que valorizavam o esforço demonstrado, direcionando o aprendizado e buscando apresentar caminhos para que os alunos criassem as soluções que se adequassem às suas ações motoras e que revelassem o prazer na participação.

O reconhecimento na Abordagem Clássica esteve fortemente direcionado aos desempenhos apresentados nas práticas das habilidades motoras especializadas da modalidade esportiva, nos resultados determinados por estes desempenhos e na conduta esportiva apresentada na prática do jogo. Foram destinados momentos nos finais de cada sessão para que o professor pudesse fazer relatos aos alunos sobre seus desempenhos motores, suas atitudes e comportamentos relativos às condutas sociais, relevando os aspectos positivos da participação nas atividades.

Com relação a dimensão "Groupping" na Abordagem de Contexto Motivacional para a Maestria foram enfatizadas as atividades em pares e grupos com o objetivo de oportunizar aos alunos livres escolhas e trocas de experiências onde o aluno pudesse exercer a autonomia sobre suas opçōes. Ainda, foi valorizada a heterogeneidade dos grupos, relativa a gênero, faixa etária, níveis de desempenho, diferenças sociais e étnicas. Todos os alunos foram encorajados a desempenhar papéis nos quais pudessem liderar grupos e estabelecer regras que primassem pela participação de todos.

Em relação às formas de agrupamento, as experiências oportunizadas pela Abordagem Clássica aconteceram conforme as características da modalidade, sendo no Tênis práticas individuais e em duplas. Ainda, foram realizadas atividades em pequenos grupos, onde os alunos praticaram jogos recreativos e de cooperação, com o objetivo de motivar e engajá-los de forma mais efetiva no programa. As escolhas dos grupos e pares foram estabelecidas pela pesquisadora/ professora, conforme os critérios por ela determinados, primando o sucesso no desempenho de todos ao participarem das atividades.

Para a dimensão "Evaluation" no Contexto Motivacional para a Maestria foram propiciadas avaliaçóes baseadas em critérios auto-referenciados, de forma individualizada e a valorizar o esforço, o engajamento e as atitudes positivas apresentadas pelos alunos. Os alunos receberam correçōes e "feedbacks" positivos sobre seus desempenhos e novas conquistas, sendo encorajados a persistir e demonstrar esforço nas suas atuações. A pesquisadora/professora utilizou dicas verbais, "feedbacks" e comentários positivos relativos aos desempenhos e condutas apresentados, com o objetivo de maximizar a participação e a motivação dos alunos. Ao longo da intervençãa, em momentos específicos forma implementadas auto-avaliações (utilizandose de desenhos de crianças executando os golpes básicos do Tênis em que os alunos coloriram e pontuaram conforme perceberam seus níveis de desempenho) e avaliações em grupo sobre progressões e novas conquistas. Ao final de cada aula, os alunos participaram de momentos de reflexão nos quais foram encorajados refletir sobre suas atitudes e relatar suas impressóes e percepçóes relativas as atividades desenvolvidas; sugerindo mudanças e reforçando os aspectos positivos da aula. Utilizandose de material didático específico (cartazes, fotos dos alunos, de jogadores, reportagens, recortes de jornais e revistas, fitas de vídeo didáticas e de jogos) os alunos construiram parâmetros para avaliarem seus desempenhos relativos às habilidades do Tênis.

Para a Abordagem Clássica, as avaliações foram baseadas nas metas estipuladas pela pesquisadora/ professora, sendo as correções técnicas efetuadas durante as execuçôes e referenciadas pelos resultados de desempenho nos jogos realizados. Como parâmetros avaliativos foram utilizados os desempenhos durante os exercícios e jogos realizados nas aulas. No final da aula pesquisadora/ professora 
reportava para as crianças as suas observações sobre atitudes demonstradas em aula e desempenhos.

Com relação a dimensão "Time" a adequação do tempo para a prática das habilidades em cada sessão foi proposta no Contexto Motivacional para a Maestria, com o respeito aos ritmos e necessidades individuais, de forma a maximizar a participação de todos. Os exercícios foram elaborados de forma a promover mudanças nos padrões motores relativos aos desempenhos das habilidades especializadas do Tênis e a disponibilidade de tempo designada às tarefas dependia dos níveis de desempenho iniciais dos alunos. Eventualmente, ocorreram alterações nos planos ou nas atividades pré-estabelecidos, quando estes se mostravam inadequados às reais capacidades e necessidades das crianças.

$\mathrm{Na}$ Abordagem Clássica, o tempo para a prática das habilidades foi determinado pela pesquisadora/ professora, conforme as necessidades de prática para a aprendizagem dos golpes básicos do Tênis. Os exercícios variaram na medida em que os alunos demonstravam domínio sobre os movimentos aprendidos, sempre seguindo uma progressão pedagógica adequada aos níveis de desempenho das crianças.

\section{Resultados}

$\mathrm{O}$ resultado do coeficiente de correlação entre teste-reteste foi de $\alpha=0,99$ indicando a fidedignidade do ins trumento para as crianças pertencentes à amostra dessa pesquisa, semelhante aos resultados do estudo piloto. $\mathrm{O}$ resultado do coeficiente de correlação entre avaliadores (pesquisador e cegado) foi de $\alpha=0,99$ evidenciando nível elevado de objetividade. $\mathrm{O}$ resultado do Teste de Normalidade Kolmogorov-Smirnov sugere que os dados apresentam-se normalmente distribuídos, $\mathrm{p}=0,20$ possibilitando a aplicação de testes paramétricos.

\section{Desempenho motor dos grupos nas habilidades especializadas do tênis}

Os resultados evidenciaram uma interação não significante entre Grupo x Tempo, $\Lambda=0,98$, F (1,59) $=1,12, \mathrm{p}=0,29, \eta 2=0,019$, poder $=0,18$, no desempenho das habilidades motoras especializadas. O tamanho do efeito associado com a interação do Grupo x Tempo foi fraco, sendo que 1,9\% da variabilidade associada pode ser atribuída a pouca diferença no desempenho entre ambas abordagens

\section{Materiais}

Foram utilizados na abordagem para a maestria: redes de tênis, redes de TNT, cercados plásticos, bolas de Tênis, bolas de Tênis "soft", bolas plásticas de diversos tamanhos e texturas, bolas de espuma em dois tamanhos, petecas, balóes, bolas de ping-pong, raquetes de Tênis em tamanhos variados, de frescobol, de pingpong, raquetes plásticas em dois tamanhos, cordas, cones em dois tamanhos, arcos, alvos, cestas e freesbees. Para a Abordagem Clássica foram utilizadas bolas soft, redes, raquetes e bolas de Tênis oficiais.

\section{Análise de dados}

Correlações (teste-reteste fidedignidade e objetividade interavaliadores); teste de Normalidade Kolmogorov-Smirnov; General Linear Model com medidas repetidas no fator tempo; ANOVAS; teste-t pareado; e, Delta com One Way ANOVA para comparaçōes nas variaçôes foram utilizados no presente estudo. O critério Wilks'lambda $(\Lambda)$ foi adotado para a General Linear Model e o nível de significância igual ou menor de $\mathrm{p}=0,05$ em todos as análises. ao longo do tempo. O efeito do Tempo para o teste de habilidades motoras especializadas do Tênis foi significante, $\Lambda=0,02, F(1,59)=2281,40, p<0,001$, $\eta 2=0,98$, poder $=1$. O teste-t pareado revelou que, para a Abordagem Clássica $(\mathrm{p}<0,05)$, o desempenho aumentou significativamente da pré (M $=73,27, \mathrm{DP}=50,46)$ para a pós-intervenção $(\mathrm{M}=$ 472,70, DP = 67,64) assim como, para a Abordagem de Contexto Motivacional para a Maestria que, da pré $(\mathrm{M}=97,90, \mathrm{DP}=68,31)$ para a pós-intervenção $(\mathrm{M}=480,03, \mathrm{DP}=77,50)$ também apresentou aumento significativo, $(\mathrm{p}<0,001)$. O efeito do Grupo para o teste de habilidades motoras especializadas do Tênis não foi significante, $F(1,59)=1,131, \mathrm{p}=$ $0,292, \eta \mathrm{h} 2=0,02$, poder $=0,18$.

$\mathrm{Na}$ avaliação das variaçōes (delta) da pré para a pós-intervenção, o grupo da Abordagem Clássica apresentou, em média, um aumento de 399,4 pontos (IC 95\%: 375,0-423,8) no desempenho das habilidades motoras especializadas do Tênis enquanto que o grupo da Abordagem de Contexto Motivacional para a Maestria teve um aumento médio de 382,1 pontos (IC 95\%: 359,2-405,0), sendo que esta diferença não 
foi estatisticamente significativa, $F(1,59)=1,118 ; \mathrm{p}$ $=0,295$. Esses resultados suportam a hipótese desta pesquisa de que as crianças do Programa de Iniciação ao Tênis em ambas as abordagens demonstrariam ganhos significativos da pré para a pós-intervenção no desempenho de habilidades motoras especializadas do Tênis. Como não houve interação entre Grupo $\mathrm{x}$ Tempo, esses resultados suportam a hipótese dessa pesquisa, de que as crianças do Programa de Iniciação ao Tênis da Abordagem de Contexto Motivacional para a Maestria apresentariam desempenhos semelhantes nas habilidades motoras especializadas do Tênis na pós-intervenção, quando comparadas aos seus pares da Abordagem Clássica (FIGURA 1 representa o desempenho nas habilidades especializadas do Tênis de ambas abordagens).

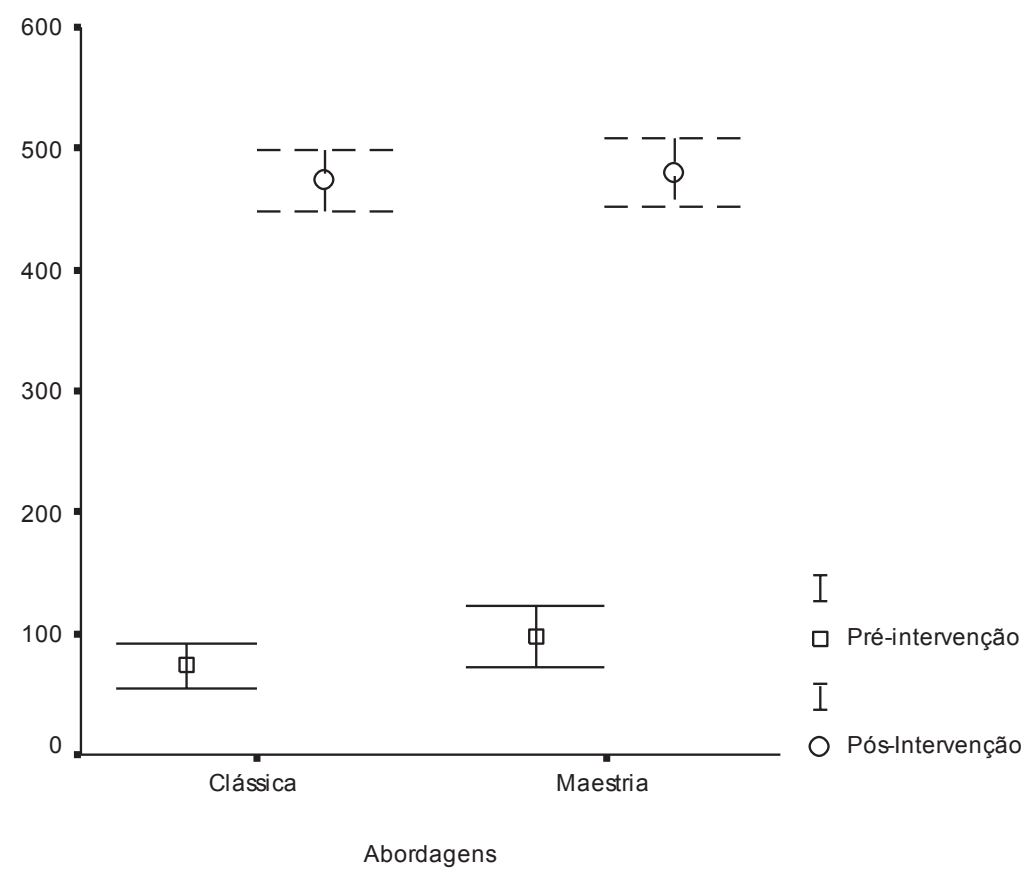

FIGURA 1 - Desempenho nas habilidades motoras especializadas do tênis das abordagens clássica e maestria na pré e na pós-intervenção.

Os resultados não evidenciaram uma interação significante entre Faixa Etária x Tempo, $\Lambda=0,99$ $\mathrm{F}(2,55)=0,156, \mathrm{p}=0,856, \eta 2=0,006$, poder $=$ 0,07 , nas habilidades motoras especializadas do Tênis. Também não evidenciaram uma interação significativa entre Grupo x Faixa Etária x Tempo, $\Lambda$ = $0,98 \mathrm{~F}(2,55)=0,664, \mathrm{p}=0,519, \eta 2=0,02$, poder $=$ 0,16 . Houve um efeito isolado significativo da Faixa Etária, $\mathrm{F}(2,55)=7,76, \mathrm{p}=0,001, \eta 2=0,22$, poder $=0,94$ onde, independentemente do grupo, os mais velhos apresentaram escores maiores nas habilidades motoras especializadas do Tênis tanto na pré quanto na pós-intervenção. Na avaliação das variações (delta) do pré para a pós-intervenção, o grupo de 6-7 anos apresentou, em média, um aumento de 386,5 pontos (IC 95\%: 337,7-435,2) no desempenho nas habilidades motoras especializadas do Tênis, o grupo de 8-9 anos apresentou um aumento médio de 398,2 pontos (IC 95\%: 375,0-421,5) e as crianças com 10 anos ou mais tiveram um aumento médio de 388, 1 pontos (IC 95\%: 363,2-413,1), sendo esta diferença não significativas, $\mathrm{F}(2,58)=0,164 ; \mathrm{p}=$ 0,849 . Os resultados suportam a hipótese de que as crianças mais velhas do Programa de Iniciação ao Tênis demonstrariam desempenhos superiores nas habilidades especializadas do Tênis. As estatísticas descritivas para cada Grupo e Faixa Etária estão descritas na TABELA 1. 
TABELA 1 - Avaliação do desempenho nas habilidades motoras especializadas do tênis conforme grupo e faixa etária.

\begin{tabular}{|c|c|c|c|}
\hline \multirow{3}{*}{ Abordagem } & \multicolumn{3}{|c|}{ Faixa etária } \\
\hline & $\begin{array}{c}6-7 \\
(\mathrm{n}=11)\end{array}$ & $\begin{array}{c}8-9 \\
(\mathrm{n}=17)\end{array}$ & $\begin{array}{c}\geq 10 \\
(\mathrm{n}=33)\end{array}$ \\
\hline & Média \pm DP & Média $\pm \mathrm{DP}$ & Média $\pm \mathrm{DP}$ \\
\hline \multicolumn{4}{|l|}{ Clássica } \\
\hline Pré-teste & $33,6 \pm 28,9$ & $68,1 \pm 36,3$ & $88,6 \pm 56,6$ \\
\hline Pós-teste & $411,8 \pm 103,4$ & $468,8 \pm 40,7$ & $493,9 \pm 58,2$ \\
\hline \multicolumn{4}{|l|}{ Maestria } \\
\hline Pré-teste & $35,5 \pm 23,0$ & $88,3 \pm 70,8$ & $124,5 \pm 64,3$ \\
\hline Pós-teste & $428,8 \pm 34,6$ & $483,8 \pm 104,2$ & $496,4 \pm 69,7$ \\
\hline \multicolumn{4}{|l|}{ Total } \\
\hline Pré-teste & $34,6 \pm 24,5$ & $77,6 \pm 54,4$ & $107,1 \pm 62,5$ \\
\hline Pós-teste & $421,1 \pm 70,4$ & $475,8 \pm 75,1$ & $495,2 \pm 63,4$ \\
\hline
\end{tabular}

Os resultados não evidenciaram uma interação significante entre Gênero x Tempo, $\Lambda=0,95 \mathrm{~F}(1$, 57) $=2,772, p=0,101, \eta 2=0,05$, poder $=0,37$, nas habilidades motoras especializadas do Tênis. Também não evidenciaram uma interação significativa entre Grupo x Gênero x Tempo, $\Lambda=0,97 \mathrm{~F}(1,57)$ $=1,65, \mathrm{p}=0,204, \eta 2=0,03$, poder $=0,24$. Porém, o efeito isolado do Gênero foi estatisticamente significativo, $\mathrm{F}(1,57)=5,448, \mathrm{p}=0,023, \eta 2=0,09$, poder $=0,63$, sendo que os meninos, independentemente do grupo, apresentaram escores maiores de habilidades motoras especializadas do Tênis tanto na pré quanto na pós-intervenção. Ainda análise das variações (delta) da pré para a pós-intervenção os meninos apresentaram, em média, um aumento de 377,1 pontos (IC 95\%: 357,1-397,2) no desempenho nas habilidades motoras especializadas do Tênis enquanto as meninas tiveram um aumento médio de 405,6 pontos (IC 95\%: 378,9-432,2), sendo esta diferença não significativa, $\mathrm{F}(1,59)=$ 3,$111 ; \mathrm{p}=0,083$. Os resultados suportam a hipótese de que os meninos do Programa de Iniciação ao Tênis demonstrariam desempenhos superiores nas habilidades especializadas quando comparados às meninas (Descritivas para Grupo e Gênero estão apresentadas na TABELA 2).

TABELA 2 -Avaliação do desempenho nas habilidades motoras especializadas do tênis conforme grupo e gênero.

\begin{tabular}{lccc}
\hline & & \multicolumn{2}{c}{ Gênero } \\
\cline { 3 - 4 } & Abordagem & $\begin{array}{c}\text { Masculino } \\
(\mathrm{n}=32)\end{array}$ & $\begin{array}{c}\text { Feminino } \\
(\mathrm{n}=29)\end{array}$ \\
\cline { 3 - 4 } Clássica & & Média $\pm \mathrm{DP}$ & Média $\pm \mathrm{DP}$ \\
& & & $46,0 \pm 28,4$ \\
& Pré-teste & $104,4 \pm 52,8$ & $467,7 \pm 80,9$ \\
Maestria & Pós-teste & $478,4 \pm 50,8$ & \\
& & & $76,3 \pm 67,5$ \\
& Pré-teste & $113,5 \pm 66,4$ & $462,0 \pm 68,4$ \\
& Pós-teste & $493,1 \pm 82,9$ & \\
& & & $59,6 \pm 51,2$ \\
& Pré-teste & $109,5 \pm 60,1$ & $465,1 \pm 74,3$ \\
\hline
\end{tabular}

158 • Rev. bras. Educ. Fís. Esporte, São Paulo, v.24, n.2, p.149-63, abr./jun. 2010 


\section{Associação entre habilidades motoras especializadas do tênis e habilidades motoras fundamentais}

Não houve associação estatisticamente significante entre os escores de habilidades motoras especializadas do Tênis e as habilidades motoras fundamentais na pré-intervenção em ambas as abordagens (Abordagem Clássica: Tênis x Locomoção: $r=-0,186 ; p=0,324$; Tênis x Controle de Objeto: $r=0,137 ; p=0,471$; Abordagem Maestria: Tênis x Locomoção: $r=0,156$; $\mathrm{p}=0,402$; Tênis $\mathrm{x}$ Controle de Objeto: $\mathrm{r}=-0,035 ; \mathrm{p}$ $=0,853)$. Na pós-intervenção houve uma associação estatisticamente significante positiva na Abordagem Maestria entre Tênis e Locomoção ( $r=0,372$; $p$ = 0,039). Em relação ao Controle de Objeto, não houve associação significante $(\mathrm{r}=0,151 ; \mathrm{p}=0,418)$.
Também não houve uma relação significativa no grupo da Abordagem Clássica (Tênis x Locomoção: $\mathrm{r}=0,164 ; \mathrm{p}=0,386$; Tênis $\mathrm{x}$ Controle de Objeto: $\mathrm{r}$ $=0,340 ; \mathrm{p}=0,066)$. Quando utilizadas as variaçóes (delta) da pré para a pós-intervenção, não houve associação estatisticamente significativa tanto para o grupo da Abordagem Clássica (Tênis x Locomoção: $r=0,042 ; p=0,824$; Tênis $x$ Controle de Objeto: $r$ $=0,122 ; \mathrm{p}=0,521)$, quanto para o grupo da Abordagem Maestria (Tênis x Locomoção: $r=0,328 ; p=$ 0,072; Tênis x Controle de Objeto: $\mathrm{r}=0,181 ; 0,331$ ). Estes resultados confirmam parcialmente, restrito a locomoção no pós-teste, a hipótese de que a prática das habilidades motoras especializadas do Tênis teria impacto moderado à forte sobre as habilidades motoras fundamentais de crianças participantes da Abordagem de Contexto Motivacional para a Maestria.

\section{Discussão}

\section{Habilidades motoras especializadas do tênis}

As crianças participantes do Programa de Iniciação ao Tênis em ambas as abordagens, Clássica e de Contexto Motivacional para a Maestria, demonstraram ganhos significativos nas habilidades motoras especializadas da pré para a pós-intervenção. Os resultados demonstram que as crianças que vivenciaram prática motora rotineira de um esporte específico adquirem, de forma consistente, habilidades motoras básicas a este esporte através da aprendizagem de seus fundamentos técnicos.

Os resultados do presente estudo são congruentes com diversos estudos prévios (AlEXANDER \& Luckman, 2001; Ames, 1992b; Browne, Carlson \& Hastie, 2004; Epstein, 1988; Siedentop, 1994; Valentini \& Rudisill, 2004a , 2004b; Wallhead \& NTOUmanis, 2004), os quais têm enfatizado a necessidade da implementação de abordagens pedagógicas alternativas no esporte, que maximizem as aquisições motoras dos aprendizes.

Como sugere o estudo de Health, Blackwell e Moddalozzo (1995), o sucesso na aprendizagem depende de uma série conjunta de fatores como, por exemplo, a qualidade da prática, o "feedback" adequado, as avaliações consistentes e os exercícios condizentes com os níveis de desempenho dos alunos, ainda que, uma abordagem mais tradicional tenha favorecido a melhoria no desempenho por meio da repetição de habilidades específicas e da frequência apropriada de "feedback". Os resultados positivos enfatizam que o aprendizado é proporcional ao número de execuções corretas de cada habilidade, bem como, às correções dos movimentos executados. Os autores salientam que o número de experiências práticas, associada ao "feedback" correto e provido em momentos adequados é fundamental para que a aprendizagem torne-se consistente. A qualidade da prática, com instruções, "feedback" e dicas verbais consistentes foi constantemente reforçada nas duas abordagens do Programas de Iniciação ao Tênis, influenciando de maneira positiva o desempenho de todas as crianças. Esses resultados reiteram a importância de desenvolver atividades práticas que conduzam a incorporação das habilidades utilizadas no esporte a ser aprendido, inserindo às práticas complexidade e especificidade do esporte, conforme sugerem LANGLEY e WoOds (1997). Ainda mais, foram implementadas atividades que atendiam as reais necessidades do jogo, oportunizando ao praticante o experimento e o gerenciamento da instabilidade gerada pelas experiências diversificadas, pressupostos esses, reforçados por CANFiELD e NeTto (1992).

Independentemente do tipo de abordagem pedagógica utilizada na iniciação ao Tênis, os ganhos motores foram, neste estudo, claramente evidenciados. Esses resultados foram ainda mais interessantes, tratando-se de habilidades específicas de um determinado contexto e considerando-se que o desempenho destas habilidades no início do 
programa era bastante pobre. E, apesar de diferenciadas pelos enfoques, ambas as abordagens foram eficientes em promover melhoras nos desempenhos dos golpes básicos do Tênis. Demonstra-se, assim, que a base motora especializada sofre mudanças positivas eficazes, quando tarefas específicas são propiciadas, ou seja, a prática deliberada refletiu em aprimoramento no repertório motor geral e específico e a especificidade da prática garantiu a especialização motora (ERICSON \& LEHMANN, 1996).

É relevante salientar que as duas abordagens de ensino dos golpes básicos do Tênis seguiram atentamente uma progressão pedagogicamente adequada às faixas etárias e aos níveis de desenvolvimento dos participantes. Ainda, quando às possíveis diferenças relativas aos desempenhos das habilidades motoras especializadas do Tênis sobre a faixa etária, os resultados demonstraram que as crianças mais velhas já evidenciavam desempenho superior no início do programa e que o mesmo foi mantido até o final, embora os ganhos nos três grupos etários tenham sido semelhantes. Levando-se em conta a complexidade do esporte, por tratar-se de um jogo em situação aberta e em que são utilizados dois materiais consecutivamente (bola e raquete), pode-se considerar que a diversidade das atividades favoreceu, desde o início do programa, tanto os mais habilidosos (crianças mais velhas) como os menos habilidosos (crianças mais jovens).

Quanto aos resultados relativos ao gênero, a pesquisa demonstra que, apesar dos meninos apresentarem melhores desempenhos em relação às meninas, tanto na pré quanto na pós-intervenção, estas evoluíram um pouco mais no decorrer do programa, embora se ressalte que essas diferenças não foram significantes. A literatura afirma que existem diferenças entre os estímulos dados pelos pais na infância conforme o gênero, encorajando os meninos a participar de maneira mais efetiva em jogos e brincadeiras mais ativas, enquanto que, para as meninas o foco se restringe às atividades mais sedentárias (HAYWOOD \& GETCHELL, 2004). Os resultados do presente estudo sugerem que as meninas que se envolvem em atividades esportivas podem se sentir encorajadas a participar efetivamente, fortalecendo seus padróes de desempenho. Quando oportunidades apropriadas de prática são oferecidas às crianças e, mais especificadamente, às meninas, estas revelam suas necessidades e potencialidades de desenvolvimento e, talvez, utilizem essas estratégias de forma consistente na busca de seu crescimento específico e global. Futuros estudos são necessários, especialmente considerando-se a marginalidade da significância destes dados.

Esta pesquisa demonstra, através dos resultados apresentados, a importância da reflexão sobre as abordagens utilizadas para a aprendizagem do Tênis, bem como de outros esportes. Ainda, reforça a necessidade da implementação de programas em que o esporte cumpra uma função de formação de crianças e jovens, considerando as necessidades individuais e permitindo aos aprendizes construir, por meio da prática lúdica, uma base sólida no seu repertório motor.

\section{Associação entre habilidades motoras especializadas do tênis e habilidades motoras fundamentais}

Os resultados apresentaram uma associação moderada e significante entre as habilidades motoras especializadas do Tênis e as habilidades motoras fundamentais no subitem locomoção para a Abordagem Maestria na pós-intervenção. Esses resultados sugerem que o Programa de Iniciação ao Tênis em contextos que priorizam a motivação e a implementação de jogos para a aprendizagem esportiva reflete em mudanças positivas sobre os movimentos de locomoção, oportunizando uma melhora nas bases motoras das crianças. Ainda, que abordagens mais clássicas, ao focalizarem a aquisição de habilidades de forma mais específica, podem estar sendo pouco efetivas no reforço de desempenhos de habilidades motoras básicas de locomoção. Assim, o presente estudo reitera, como alguns autores (BELKA, 1994; Gallahue \& Ozmun, 2001) que, adequando o uso de materiais de fácil manipulação, utilizando tarefas adequadas aos níveis de desempenho, motivadoras e desafiantes, o aluno tem a chance de desempenhar as habilidades do jogo de forma mais fácil e praticá-lo intensivamente, tornando tais habilidades mais complexas e consistentes. Este estudo revela o impacto de abordagens que priorizam o desenvolvimento do aluno como um todo e salienta a importância de novas investigaçōes relativas à eficácia da implementação de intervençōes que considerem a contextualização do aprendizado às necessidades e expectativas dos alunos e que qualifiquem as aulas de educação física e a aprendizagem de esportes específicos. 


\section{Conclusões}

Ao propiciar programas de intervenção voltados à aprendizagem do Tênis, foram criadas condições para que os alunos pudessem, além de desfrutar do prazer da prática, experienciar uma aprendizagem condizente com os seus padróes desenvolvimentistas. Assim, apesar dos diferentes meios utilizados pelas duas abordagens para a aprendizagem do Tênis, ambas demonstraram ser efetivas quanto às aquisiçôes dos golpes básicos em níveis iniciantes. As crianças apresentavam, no início da intervenção, baixos desempenhos quanto às habilidades motoras nos golpes básicos do Tênis, em decorrência de pouca ou nenhuma experiência prévia no esporte. Tratando-se de um esporte com altos níveis de exigência quanto ao desempenho motor específico, os professores de Programas de Iniciação ao Tênis devem considerar que uma aprendizagem com sucesso se dará na medida em que forem incorporadas a qualidade e o tempo adequados de vivências necessárias, no presente estudo de seis meses, para que se possam atingir os objetivos de aprimoramento motor. Ainda, ambas as abordagens contemplaram a todos os participantes, propondo atividades apropriadas, respeitando as faixas etárias e condizentes com os níveis de desempenho dos golpes básico do Tênis de crianças escolares.

As abordagens implementadas no programa contemplaram aos alunos experiências motoras em atividades que primaram pelo objetivo principal do Tênis, que é o jogar. Essas atividades permitiram a utilização das habilidades motoras específicas adquiridas em situações de jogos, sendo eles adaptados ou oficiais. Ainda, a aprendizagem das regras, dos rituais e a participação em competiçôes internas fortaleceram o conhecimento global do esporte e o engajamento dos participantes.

O sucesso na aprendizagem depende da qualidade das experiências práticas, do encorajamento aos alunos para participar, das respostas positivas aos comportamentos e desempenhos e do envolvimento por parte de alunos e educadores nas atividades. Propostas metodológicas que possibilitem uma maior e mais variada quantidade e qualidade de experiências, assim como, que respeitem as diferenças e ritmos individuais, devem ser utilizadas pelos educadores na intenção de maximizar o aprendizado e torná-lo momento de alegria e prazer. Estratégias de aprendizagem como diversas dinâmicas de jogos e/ou o uso de drills devem ser implementadas com o objetivo de potencializar o aprendizado e o engajamento no esporte. Ambas as estratégias podem ser utilizadas conforme os objetivos traçados pelos educadores, conjuntamente às expectativas dos alunos. Ainda, deve ser considerado o interesse dos alunos para aprender as habilidades específicas que compóem os jogos ou os esportes em que eles se encontram engajados. Da mesma forma, deve-se considerar a qualidades das tarefas propostas, com variedade e diversificação, como também, a especificidade e a pertinência das dicas verbais e dos "feedbacks" propiciados aos alunos, no intuito de conscientizá-los de seus desempenhos e de promover mudanças necessárias para a aquisição de novas habilidades. Ainda, o Tênis pode tornar-se um importante instrumento de inserção social, este deveria ter sua prática incorporada além dos clubes, como também em escolas e parques públicos, a fim de contemplar um maior número de praticantes.

\section{Abstract}

Tennis specialized skills: a beginning sport intervention study with school children

The purpose of the present study, with a quasi-experimental and correlational design, was to verify the influence of a Beginning Tennis Program (BTP) with two approaches - the Classical approach (CA) and the Mastery Motivational Climate approach (MA) - on the development of specialized tennis motor skills (STMS) and the associations between the specialized skills and fundamental skills. The participantes were 61 children (29 girls and 32 boys), aged 6-12 yr. $(M=9.4)$. Thirty children were submitted to the CA and 31 to the MA. The children were assessed using the Test of Gross Motor Development-2 (TGMD-2) and the Specialized Tennis Motor Skills instrument. The BTP was carried out in 26 weeks and implemented for MA the assumptions of the TARGET structure and the Sport Education Model, and for $C A$ the classical models for tennis learning. Results indicated that 1) all children showed positive and significant changes $(p<0.01)$ in STMS; 2$)$ there was a non significant interaction of age group $(p=$ 
$0.519)$ and gender ( $p=0.24)$ on STMS; 3 ) a restrict association in the post test between locomotor skills and specialized skills for the Mastery group. The implementation of a Beginning Tennis Program based on effective methodological proposals that are suitable for the participants' real needs fosters motor gains that reinforce children development.

UNITERMS: Learning; Motor skills; Tennis.

\section{Referências}

ALEXANDER, K.; LUCKMAN, J. Australian teacher's perceptions and uses of the sport education curriculum model. European Physical Education Review, Manchester, v.7, p.243-67, 2001.

AMES, C. Achievement goals, motivational climate and motivational processes. In: ROBERTS, G.C. (Ed.). Motivation in sport and exercise. Champaign: Human Kinetics, 1992a.

Classrooms: goals, structures, and student motivation. Journal of Educational Psychology, Washington, v.84, n.3, p.261-71, 1992b.

ARAÚJO, D.; DAVIDS, K.; SERPA, S. An ecolocical approach to expertise effects in decision-making in a simulated sailing regatta. Psychology of Sport Exercise, Amsterdam, v.6, p.671-92, 2005.

ARBEITSMATERIALEN Zur Differentiellen Bewegungsanalyse Der Grundschlage im Tennis, Hannover 1977.

BALBINOTTI, M.A.A.; BALBINOTTI, C.A.A.; MARQUES, A.T.; GAYA, A. Proposição e validação de um instrumento para avaliação do treino técnico-desportivo de jovens tenistas. Revista Brasileira de Educação Física e Esporte, São Paulo, v.18, n.3, p.213-26, 2004.

BELKA, D.E. Teaching children games: becoming a master teacher. Champaign: Human Kinetics, 1994.

BENTO, J.; GARCIA, R.; GRAÇA, A. Contextos da pedagogia do desporto. Lisboa: Livros Horizonte, 1999.

BROWNE, T.B.J.; CARLSON, T.B.; HASTIE, P.A.A comparison seasons presented in traditional and sport education formats. European Physical Education Review, Manchester, v.10, p.199-214, 2004.

BURWASH, P. Total tennis: a complete guide for today players. New York: Collier Books, 1991.

CANFIELD, M.S; FERREIRA NETO, C.A. Aprendizagem da tarefa de rebater sob duas condições diferentes de incerteza ambiental em crianças de 6 a 9 anos de idade. Revista Brasileira de Ciências do Esporte, Campinas, v.16, n.2, p.14-21, 1995. CLARK, J.E.; METCALFE, J.S. The mountain of motor development: a metaphor. In: CLARK, J.E.; HUMPHREY, J.H. (Eds.). Motor Development: Research and Reviews. Reston: NASPE, 2002. v.2., p.163-90.

DENIAU, G. Tenis: técnica, táctica y entrenamiento. Barcelona: Paidotribo, 1997.

DOOLITTLE, S. Teaching net games to skilled students: a teaching for understanding approach. Journal of Physical Education, Recreation and Dance, Reston, v.66, n.3, p.18-23, 1995.

DOUGLAS, P. Manual de tenis. Madrid: Blume, 1982.

EPSTEIN, J. L. Effective schools or effective students? Dealing with diversity. In: HAWKINS, R.; MacRAE, B. (Eds.). Policies for America's public schools. Norwood: Ablex, 1988. p.78-97.

ERICSON, K.A; LEHMANN, A.C. Expert and exceptional performance: evidence of maximal adaptation to task constraints. Annual Review of Psychology, Palo Alto, v.47, n.1, p.273-305, 1996.

GALLAHUE, D.C.; OZMUN, J.C. Compreendendo o desenvolvimento motor bebês, crianças, adolescentes e adultos. São Paulo: Phorte, 2001.

GALLIETTE, R. Tênis: metodologia do ensino. Rio de Janeiro: 1996.

GALLWEY, T.W. O jogo interior de tênis. São Paulo: Textonovo, 1996.

GAYA, A.; MARQUES, A.; TANI, G. (Orgs.). Desporto para crianças e jovens: razões e finalidades. Porto Alegre: Editora da UFRGS, 2004.

GRAÇA, A. O desporto na escola: enquadramento da prática. In: GAYA, A.; MARQUES, A.; TANI, G. (Orgs.). Desporto para crianças e jovens: razōes e finalidades. Porto Alegre: Editora da UFRGS, 2004.

HAYWOOD, K.M.; GETCHELL, N. Desenvolvimento motor ao longo da vida. 3 ed. Porto Alegre: Artmed, 2004. HEATH, E.M.; BLACKWELL, J.R.; MADDALOZZO, J.G.F. Teaching beginning tennis: a versatile drill formation. Journal of Physical Education, Recreation and Dance, Reston, v.66, n.8, p.14-6, 41-2, 1995. 
JEWETT, A.E.; BAIN, L.L.; ENNIS, C.D. The curriculum process in physical education. 2 ed. Madison: Brown \& Benchmark, 1995.

LAGUNA, M. Adaptar o treino à natureza do desporto que se pratica. In: ARAÚJO, D. (Ed.). O contexto da decisão: a acção tática no desporto. Lisboa: Visão e Contextos, 2005.

LANGLEY, D.J.; WOODS, A.M. Developing progressions in motor skills: a systematic approach. Journal Physical Education, Recreation, and Dance, Reston, v.68, n.7, p.41-5, 1997.

LENDL, I.; MENDOZA, G. Super tenis con Ivan Lendl. Barcelona: Martinez Roca, 1987.

MARQUES, I. Arremessar ao alvo e à distância: uma análise de desenvolvimento em função do objetivo da tarefa. Revista Paulista de Educação Física, São Paulo, v.10, n.2, p.122-38, 1996.

MEINECKE, B.; SCHOTH, R. Tenis para ninõs. Barcelona: Martinez Roca, 1985.

MESQUITA, I. Refundar a cooperação escola-clube no desporto de crianças e jovens. In: GAYA, A.; MARQUES, A.; TANI, G. (Orgs.). Desporto para crianças e jovens: razões e finalidades. Porto Alegre: Editora da UFRGS, 2004.

A contextualização do treino no voleibol: a contribuição do construtivismo. In: ARAÚJO, D. (Ed.). O contexto da decisão: a acção tática no desporto. Lisboa: Visão e Contextos, 2005.

METZLER, M.W. Teaching in competitive games: not just playing around. Journal of Physical Education, Recreation and Dance, Reston, v.61, n.8, p.57-61, 1990.

SIEDENTOP, D. Sport education: quality PE trough positives sport experiences. Ohio: Human Kinetics, 1994.

STURM, K. Ténis. Lisboa: Estampa, 1982.

THEEBOOM, M.; KNOP, P.; WEISS, M.R. Motivational climate, psychological responses, and motor skill development in children's sport: a field-based intervention study. Journal of Sports \& Exercise Psychology, Champaign, v.17, p.294-311, 1995.

TILDEN, W.T. Tênis: como jogá-lo melhor. São Paulo: Pioneira, 1982.

VALENTINI, N. C. Influência de uma intervenção no desempenho motor e na recepção de competência de crianças com atrasos motores. Revista Paulista de Educação Física, São Paulo, v.16, p.61-75, 2002.

VALENTINI, N.C.; RUDISILL, M.E. Effectiveness of an inclusive mastery climate intervention on the motor skill development of children with and without disabilities. Adapted Physical Activity Quarterly, Champaign, v.21, p.330-47, 2004a.

Motivational climate, motor-skill development and perceived competence: two studies of developmentally delayed

kindergarten children. Journal of Teaching in Physical Education, Champaign, v.23, p.216-34, 2004 b.

VALENTINI, N.C.; RUDISILL, M.E.; GOODWAY, J.D. Incorporating a mastery climate into physical education: it's developmentally appropriate! Journal Physical Education, Recreation, and Dance, Reston, v.70, n.7, p.28-32, 1999a.

Mastery climate: children in charge of their own learning. Teaching Elementary Physical Education,Champaign, v.10, p.6-10, 1999 b.

VALENTINI, N.C.; TOIGO, A.M. Ensinando educação física nas séries iniciais: desafios \& estratégias. Porto Alegre: Salles, 2005.

WALLHEAD, T.L.; NTOUMANIS, N. Effects of a sport education intervention on students' motivational responses in physical education. Journal of Teaching in Physical Education, Champaign, v.23, p.4-18, 2004.

WEISS, M. Psychological skill development in children and adolescents. The Sport Psychologist, Champaign, v.5, p.335-54, 1991.

YOUNG, J.F. When practice doesn't make perfect: improving game performance in secondary level physical education classes. Journal of Physical Education, Recreation and Dance, Reston, v.56, n.8, p.24-6, 1985.

ENDEREÇO

Nadia Cristina Valentini

Laboratório de Pesquisa

Escola de Educação Física

Universidade Federal do Rio Grande do Sul

R. Felizardo, 750 - Jardim Botânico

Recebido para publicação: 18/10/2008

Revisado em: 14/08/2009

Aceito: 16/09/2009

e-mail: nadiacv@esef.ufrgs.br 